\title{
Elementary School Students Learn Arduino Programming to Assemble Sensory-Controlled Works
}

\author{
Chow-Chin Lu, Jon-Chao Hong, Fen-Fang Chen, and Shin-Yin Ma
}

\begin{abstract}
This study aims to design a cross-disciplinary science, technology, engineering, and mathematics (STEM) curriculum for the elementary school students in order to cultivate their STEM literacy. In this case study, 54 students from fifth-six grade of elementary school were included as research samples. The subject research course of "Arduino programming to assemble sensory-controlled works" was designed by seven teachers from various fields. The data collected included Arduino learning sheets, assemble sensory-controlled works, semi structured interviews, and t-test of pre-test and post-test of STEM literacy test. The conclusions were: 1). during the implementation, each group of students who created design Arduino programming and assembled sensory-controlled works learned to select appropriate materials, pedestal, and measuring. 2). After the teaching, elementary school students could improve STEM literacy including each component, the amount of experimental effect of each component of STEM literacy was medium to high.
\end{abstract}

Index Terms-Arduino programming, cross-disciplinary curriculum, assemble sensory-controlled works, STEM literacy.

\section{INTRODUCTION}

Most elementary school information courses teach students how to use word software and simple 3D printing, and they begin to teach programming until the middle high school in Taiwan [1]. Programming is very important, if elementary school students do not learn programming, they may not be able to catch up with the challenges of technology products and cannot use technology products correctly. This study explores the feasibility of Arduino programming to assemble sensory-controlled works for the senior students of elementary school. It is necessary to teach these students Arduino programming to control three kinds of sensors such as RGB three-color LED lights, buzzer and infrared sensor [2]. The Arduino integrated development environment (IDE) is a cross-platform application for Windows that is written in the programming language Java or language $\mathrm{C}$ [3]. ArduBlock is a downloadable tool that runs as an overlay to the official Arduino IDE. The final product won't be any different to a program built using the normal process, so it's a

Manuscript received October 1, 2019; revised February 29, 2020.

Chow-Chin Lu is with the Department of Science Education, National Taipei University of Education, Taiwan (e-mail: luchowch@tea.ntue.edu.tw).

Jon-Chao Hong is with the Department of Industrial Education, National Taiwan Normal University, Taiwan (e-mail: tcdahong@gmail.com).

Fen-Fang Chen is with the Taipei City Ren-Ai Elementary School, Taiwan (e-mail: ffchen2005@yahoo.com.tw).

Shin-Yin Ma is with the New Taipei City Guang-Hua Elementary School, Taiwan (e-mail: ange1829a@hotmail.com). great first step if you're just getting started [4]. In addition, in response to the reforms in the STEM (Science, Technology, Engineering, and Mathematics) curriculum in the world [5], Bybee clearly articulates that the overall purpose of STEM education is to develop a STEM literate society, emphasize that students learn STEM literacy to meet social, economic and personal needs [6], [7]. This study also emphasizes the STEM literacy of elementary school students, and develops subject research course of "Assembly Green Buildings" in conjunction with the sixth grade course, and "Assembling Animal Beast" in conjunction with the fifth grade course. Science teachers teach students to understand the function of green buildings or the special habits of various animals. Craft teachers teach students how to choose the appropriate pedestal, materials to assemble green building or animal beast. Then, collaborative teaching of information, science, and craft teachers, teaching elementary school students to learn Arduino programming to assemble green buildings or animal beasts; under the control of each group of students, these sensory-controlled works could be stimulated to respond accordingly, such as opening windows of green building. Collaborative teaching can train each group of students to organize cross-disciplinary knowledge to solve problems and cultivate STEM literacy [8], [9]. The collaborative teachers and each group of students form a close synergy relationship, and work together to complete the teaching activities, giving full play to the team spirit of teaching and learning [10], [11]. There are two aims for this study:

1) To design a subject research course of assemble sensory-controlled works by two experts and five collaborative teachers, elementary school students learn Arduino programming to express the effectiveness of the sensory-controlled works.

2) To cultivate students' STEM literacy in the subject research course and analyze its effectiveness among fifth grade and sixth grade students in assemble sensory-controlled works.

\section{METHODOLOGY}

\section{A. Research Design and Structure}

This study adopted a case-study method to design subject research course on "Green building sensory-controlled works" and "Animal beast sensory-controlled works". It made use of STEM Literacy Test (SLT) pre-test and post-test design during before and after the students studied this course. $T$-test of pre-test and post-test of SLT combined with the semi-structured interviews to explore students how to 
assemble sense-controlled works and cultivate STEM literacy.

\section{B. Research Object}

The sample comprised 54 students who were in fifth-sixth grade at the large elementary school in Taiwan. There were 26 sixth grade students and 28 fifth grade students. The samples were in normal classes with 12 other classes in the same grade, and the semester scores were no different from those of other classes. The samples have learned Scratch digital technology, which has some basics for building block programming, but they have not been exposed to Arduino programming, nor had any experience in assembling sensory-controlled works.

\section{Course Design and Implementation}

The subject research course required planning and adjustment. The team included seven of technical education curriculum experts, science researcher and the collaborative teachers. The subject research course was divided into five-grade one class, and six-grade another class. The design description of the two-class subject research course was shown in Table I.

TABLE I: DESIGN DESCRIPTION OF THE TwO-CLASS SUBJECT RESEARCH COURSE

\begin{tabular}{|c|c|c|c|c|}
\hline teaching objectives & teaching content & teaching methods & teaching time & teaching teacher \\
\hline 1. Cross-disciplinary & Green building & Film teaching & \multirow[t]{3}{*}{2 lessons } & information teacher \\
\hline 2. Students are interested & Animal beast & \multirow[t]{2}{*}{ Question and answer } & & 2 science teachers \\
\hline 3. sensory-controlled works & Test its function & & & \\
\hline 2. Solve problem of the & \multirow{2}{*}{$\begin{array}{l}\text { RGB three-color LED light, } \\
\text { buzzer, infrared sensor }\end{array}$} & Practice & \multirow{2}{*}{2 lessons } & 2 science teachers \\
\hline sensor-controlled loop & & Solve the problem & & \\
\hline 1. Sensory work design & Design blueprint & Demonstration teaching & \multirow[t]{3}{*}{2 lessons } & 2 craft teachers \\
\hline 2. Select materials & Select base and material & Student report work content & & 2 science teachers \\
\hline 3. Select the base of works & Proportion and symmetry & Discussion and suggestion & & \\
\hline 1. Assemble sense-controlled works & Each group assembly works & Assembly and testing & \multirow{3}{*}{$\begin{array}{l}2 \text { months, after } \\
\text { school time }\end{array}$} & information teacher \\
\hline 2. test sense-controlled works & Each group test works & Discussion and suggestion & & 2 craft teachers \\
\hline & & Rolling correction & & 2 science teachers \\
\hline
\end{tabular}

Subject teaching included: 1) the science teacher taught the function of the green building, and the habits of the animal beast. It is not appropriate to overestimate other aspects. 2) The information teacher taught Arduino programming, using RGB three-color LED lights, buzzers, and infrared sensors to manipulate "sensory-style works". It was not appropriate to over-infer other technologies. 3) The craft teacher taught how to draw the design drawings, selection materials and pedestals of the "sensory-controlled works", and mathematical concepts such as measurement, volume, and proportion. Implement teaching included: 1) each group of students designed Arduino programs to manipulate "sensory-controlled work" to solve the performance and loop problems of various sensors-controlled work. 2) Each group of students chose the right material and pedestal to assemble the "sensory-controlled work", all the sensors should be put into the "sensory-controlled work". 3) Each group of students tested the function of the "sensory-controlled work" and made a rolling correction to optimize it. This was a case study in Taipei City, and it was not appropriate to overestimate the classes of all schools in Taiwan.

\section{Measure}

The STEM literacy test was used to analyze the changes in the STEM literacy of students learn Arduino programming to assemble sensory-controlled works. The content of SLT test comprised "Greenhouse effect", "Green building", "Arduino programming" and "Animals", was in Table II.

TABLE II: QUESTION GROUP, QUESTION NUMBER, FIELD, AND ORIENTION GOAL OF SLT

\begin{tabular}{|c|c|c|c|}
\hline Question group & Question number (question type, score) & field & Orientation goal \\
\hline \multirow[t]{3}{*}{ 1. Greenhouse effect } & 1. ( choice question, 1 ) & mathematics & Identify mathematical graphs \\
\hline & 2. ( Questions, 1-3) & mathematics & Analysis chart data of greenhouse effect \\
\hline & 3. ( choice question, 1 ) & science & Understand environmental issues \\
\hline \multirow[t]{4}{*}{ 2. Green building } & 4. ( choice question, 1 ) & science & Understand green building knowledge \\
\hline & 5. ( choice question, 1 ) & engineer & Confirmation of engineering materials \\
\hline & 6. ( choice question, 1 ) & engineer & Construction engineering design \\
\hline & 7. ( calculation, 1-3 ) & engineer & Can apply engineering concepts \\
\hline \multirow[t]{4}{*}{ 3. Arduino programming } & 8. ( choice question, 1 ) & technology & Processing message information \\
\hline & 9. ( Questions, 1 ) & technology & Conceptual Arduino module \\
\hline & 10. ( Questions, 1-2 ) & technology & Constructing Arduino elements \\
\hline & 11. ( choice question, 1 ) & technology & Understand Arduino terminology \\
\hline \multirow[t]{3}{*}{ 4. Animals } & 12. ( choice question, 1 ) & mathematics & Logical thinking of life question \\
\hline & 13. ( choice question, 1 ) & science & Use scientific interpretation \\
\hline & 14. ( choice question, 1 ) & science & Understand the reasons of animal habits \\
\hline
\end{tabular}

Descriptive statistics and $t$-test analysis of the SPSS 22.0 statistical analysis software were used to explore whether the 
subject research teaching strategy improved STEM literacy of elementary school students in learning Arduino programming to assemble sensory-controlled works. The SLT test was conducted with 160 elementary school students in Taiwan, and analyzed by SPSS 22.0 software. There were four factors: scientific literacy, technical literacy, engineering literacy, and mathematical literacy after KMO and Bartlett's verification. The internal consistency $\mathrm{KR}_{21}$ of the total scale is 0.759 , and the four components are sequentially $0.596,0.581,0.605$, and 0.527 . The average difficulty was 0.45 , and the average discrimination was 0.43 .

\section{E. Data Analysis}

In this study, the research questions, data collection and data analysis were shown in Table III.

TABLE III: THE RESEARCH QUESTIONS, DATA COLLECTION AND DATA

\begin{tabular}{|c|c|c|}
\hline Research aims & $\begin{array}{l}\text { Data } \\
\text { collection }\end{array}$ & Data analysis \\
\hline $\begin{array}{l}\text { 1. elementary school students } \\
\text { learn Arduino } \\
\text { programming to express } \\
\text { the effectiveness of } \\
\text { assembly the } \\
\text { sensory-controlled works }\end{array}$ & $\begin{array}{l}\text { 1. Arduino learning } \\
\text { sheet } \\
\text { 2. assemble } \\
\text { sensory-controlled } \\
\text { works } \\
\text { 3. interview }\end{array}$ & $\begin{array}{l}\text { 1. Analyze } \\
\text { contents of } \\
\text { Arduino } \\
\text { learning sheet } \\
\text { 2. Analysis and } \\
\text { comparison } \\
\text { 3. Explain the } \\
\text { meaning of } \\
\text { interviews }\end{array}$ \\
\hline $\begin{array}{l}\text { 2. Analyze STEM literacy } \\
\text { effectiveness among fifth } \\
\text { grade and sixth grade } \\
\text { students in assembly the } \\
\text { sensory-controlled works. }\end{array}$ & $\begin{array}{l}\text { 1. learning sheet, } \\
\text { design drawings, } \\
\text { works, interview } \\
\text { 2. result of STEM } \\
\text { literacy test }\end{array}$ & $\begin{array}{l}\text { 1. Perform } \\
\text { classification } \\
\text { and coding of all } \\
\text { materials to } \\
\text { form a claim } \\
\text { 2. } t \text { test of SLT }\end{array}$ \\
\hline
\end{tabular}

\begin{tabular}{ll}
\hline & pre-test and \\
& post-test with \\
& research \\
& samples \\
\hline
\end{tabular}

This study was coded by grounded theory, its intrinsic validity was established by three professors in the different field, and three senior teachers in elementary school. They read all the qualitative materials, give classification and explanation, and reach a consensus of consistency. External validity was established by above six members to sort out various qualitative data, analyze and summarize, through triangle correction and continuous comparison to form a claim. The STEM literacy test scores obtained were analyzed using SPSS 22.0 as descriptive statistics, and $t$ test of SLT pre-test and post-test with research samples.

\section{RESEARCH RESULTS AND ANALYSIS}

\section{A. Arduino Programming to Manipulate Sensory-Controlled Works}

After information teacher' demonstration, each group of students used Arduino programming to present the expression of the sensory-controlled work. For example, a group of fifth grade students designed buzzer programming showed that the field behavior of the assemble frog beast sensory-controlled work was shown in Fig. 1.

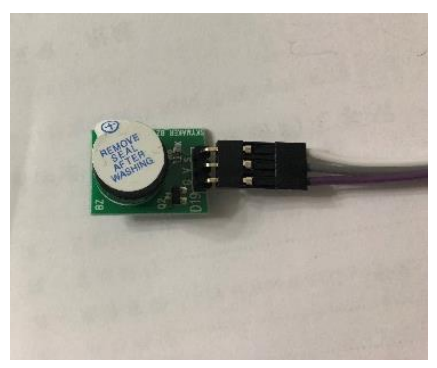

1. Connect the buzzer to the e-board

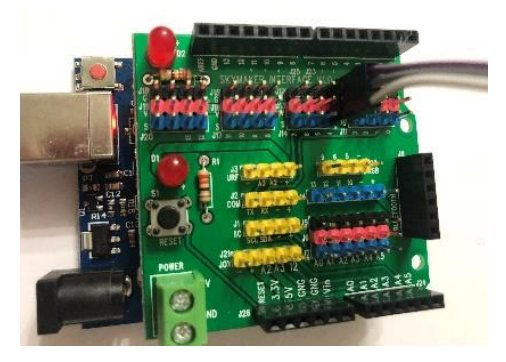

2. Connect the wires to a three-hole connection

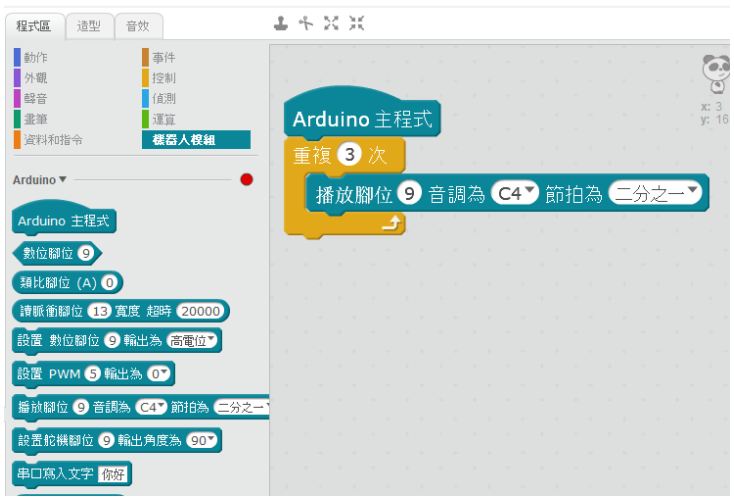

3. Buzzer Arduino programming

Fig. 1. The fifth-grade students designed the Arduino program to generate a "buzzer tweet" to announce the field of the frog beast.

From the all student's learning process, they could design a foot signal to control a module when they programed an Arduino expansion e-board. But when students designed more than two Arduino expansion modules, they must have designed a foot signal to control two modules or even multiple foot signals, they would encounter module signals cannot correctly correspond to foot signal. The interview of the information teacher was explained: "Because students didn't have the experience of programming, and their logic thinking was not enough, I must guide students to design correct loop of a foot signals to control multiple modules (interview teacher1)." Finally, each group can complete the task, took the first group of fifth grade making "announce the field of frog beast" as an example. First group used the infrared sensor to sense that other male frogs were approaching, the buzzer started to scream and was increasingly loudly proclaiming its field. The sixth grade students designed the "Sense-controlled green building", their Arduino programming was more creative. They wrote the program to open the window half or fully according to the temperature rise. They could also write the Arduino programming to mix the RGB three-color LED light into a purple light.

\section{B. Analysis of "Sense-Controlled Works" Assembly by Each Group of Students}

All the collaborative teachers jointly guided each group of students to assemble the "sensory-controlled works". Their process was design drawing, assembly operation, correction 
design drawing, reassembly operation, and completion of "sense-controlled work" assembly. The sixth grade students learned how to use the Arduino expansion e-board, light sensor, infrared sensor and other parts to assemble "the green building sense-controlled works", so did the fifth grade students to assemble "the animal beast sense-controlled works". Take the second group of sixth grade students' assembled green building sense-controlled works as an example was shown in Fig. 2.

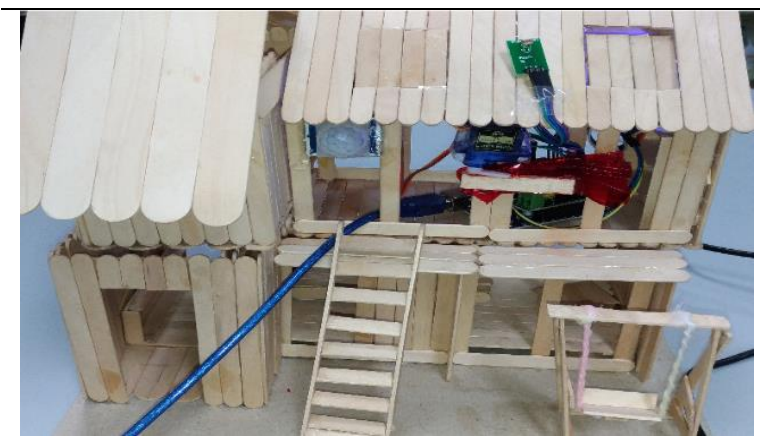

They assembled two sunroofs that automatically opened due to temperature rise to a certain degree, using tape to mount the sense-controlled expansion board on the floor-to-ceiling window posts.

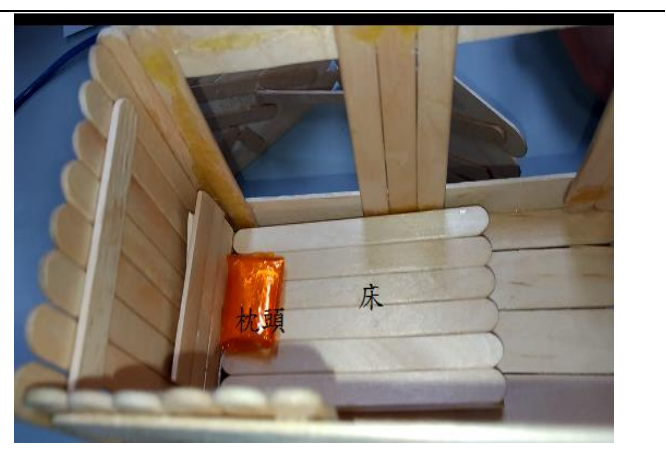

There were large floor-to-ceiling windows in the green building sense-controlled works to adjust the temperature rise to a certain degree, and there were furnishings, pillows, furniture in the house.

Fig. 2. The second group of students assembled the "green building sense-controlled works".

They assembled two sunroofs that automatically open due to temperature rise to a certain degree, using tape to mount the sense-controlled expansion e-board on the floor-to-ceiling window posts. There were large floor-to-ceiling windows in the green building sense-controlled works to adjust the temperature, and there were furnishings, pillows, furniture in the house. The interview of the second group of students was explained: "Designed the Arduino program to control the temperature sensitive detector to turn on sunroof and window at the same time. When the infrared sensor was sensed person approaches, the RGB blue light would turn into green light (interview group 2)".

When assembling animal beasts in the fifth grade class, craft teachers had more guidance, took the seventh group making "color-changing octopus beast" as an example. This group wanted to express the softness and color change reaction of the octopus beast. Craft teachers guided them to use the transparent tracing paper to wrap PET bottle as the octopus body to see the color change of the RGB tri-color LED lights, and made 8 feet with the curly tracing paper showing the softness of the octopus beast.

\section{Elementary School Students Implement "Sense-Controlled Works" to Cultivate STEM Literacy}

The results of dependent sample T-test of pre-test and post-test of STEM literacy test in the fifth grade and sixth grade classes with a total of 54 students were shown in Table IV.

TABLE IV: SUMMARY OF T TEST OF STEM LITERACY TEST IN DIFFERENT GROUPS

\begin{tabular}{|c|c|c|c|c|c|c|c|}
\hline \multirow{2}{*}{ STEM LITERACY TEST } & \multicolumn{2}{|c|}{ PRE-TEST } & \multicolumn{2}{|c|}{ POST-TEST } & \multirow{2}{*}{$t$} & \multirow{2}{*}{$p$} & \multirow{2}{*}{$E S$} \\
\hline & M & SD & $\mathrm{M}$ & SD & & & \\
\hline Total amount & 8.08 & 3.292 & 12.72 & 2.918 & -16.060 & .000 & 1.409 \\
\hline Scientific literacy & 2.42 & 1.046 & 3.04 & .919 & -4.350 & .000 & 0.593 \\
\hline Technical literacy & 2.26 & 1.389 & 3.83 & 1.005 & -7.473 & .000 & 1.130 \\
\hline Engineering literacy & 1.49 & 1.310 & 3.17 & 1.090 & -9.316 & .000 & 1.282 \\
\hline Sixth grade $(N=26)$ & 9.28 & 2.865 & 14.12 & 2.783 & -8.852 & .000 & 1.689 \\
\hline Fifth grade $(N=28)$ & 7.00 & 3.322 & 11.46 & 3.066 & -17.542 & .000 & 1.343 \\
\hline
\end{tabular}

$* * * p<0.001$

From the results in the table, it could be noted that the interactions among the change of before and after two classes of students' study reached a significant level. The amount of experimental effect of each component of STEM literacy was medium to high, represented that two classes of students learning the subject research course could improve STEM literacy including each component. Sixth grade students received an average scores of SLT higher than fifth grade students, represented that STEM literacy of sixth-grade students was better than that of fifth-grade students. The five teachers who participated in this teaching thought that the thinking intelligence of the sixth-grade students had entered the formal operational stage, and their thinking ability was more mature than the fifth-grade students in the concrete operational stage. The sixth-grade students were more able to think, calculate and reason about problems, so their STEM 
literacy is better than fifth grade students.

The most advanced STEM literacy for students was technical literacy and engineering literacy. The test questions of technical literacy are related to Arduino design. Students learned from the subject research course and took a lot of time to understand Arduino e-board and Arduino programming, so they could understand the technical questions and answer correctly. The test questions of engineering literacy are related to choose the most appropriate material and design. From the assembly of sensory-controlled works, students learned to choose the most appropriate materials and pedestals, and adjusted the way of production when facing assembly problems, so they could improve engineering literacy. The interview of the student was explained: "Assembling animal beasts allowed me to know the importance of choosing materials. If the choice was wrong, we must remove the works and redo. We were more and more cautious in choosing the appropriate materials to assemble the works. Later, when taking the engineering literacy test, I also learned to be cautious (interview student-5- 7)". The third improvement of STEM literacy for the students was the mathematical literacy. Students could understand the importance of accurate measurement when assembling sensory-controlled works. If the measurement was wrong, the works should be removed and redone. They also learned to read charts, measure spaces and shapes, and these studies could enhance their mathematical literacy. In order to assemble sensory-controlled works such as green buildings and animal beasts, students should read many scientific articles on heat conduction, heat convection, heat radiation, and animal special habits, and that could enhance their scientific literacy.

\section{CONCLUSION}

Implementing Arduino programming to assemble sensory-controlled works could enhance the STEM literacy of elementary school students: the subject research course teaching and the results of statistical analysis of the STEM literacy test showed that elementary school students who implemented subject research learning were taught in cross-disciplinary fields. There is a significant improvement in design drawing, assembly operation, and STEM literacy, with the SLT post-test results of elementary school students being significantly better than SLT pre-test. This confirmed that the elementary school students could receive via the Arduino e-board connections, such as buttons, switches, and sensors (sound, light), and were able to control these electronic devices through programs written in the development environment [12]. The assembly sensory-controlled works could be implemented, thereby promoting the elementary school students' performance in assembling work skills, including choose the appropriate pedestal, materials, and measuring. Elementary school students were brave enough to accept the challenges of the new course and assemble sensory-controlled works. The collaborative teachers' jointly teaching strategy has been affirmed and endorsed by most elementary school students; they believed that the cross-disciplinary course can enhance their motivation, and opportunities for communication between teachers and students. Collaborative teaching can integrate the expertise of the teacher group, establish a goal-oriented professional relationship, effectively apply the existing teaching environment to plan multiple courses and assessments, and achieve the appropriate teaching objectives for cultivating students' individual differences.

\section{IMPLICATIONS}

In response to curriculum reform of 12-year compulsory education in Taiwan, teachers are playing an important role in the development of inquiry teaching and implementation. Learning Arduino and Scratch programming is a category in the middle high school, and it is not necessary to learn in the elementary school in Taiwan. This subject research course was brought elementary school senior students to learn Arduino programming to assemble sensory-controlled works and found it feasible. This showed that the elementary teachers in different fields collaborate to design STEM subject research course, which can enhance the inquiry and implementation of elementary school senior students and promote their STEM literacy. Therefore, it was recommended to develop a cross-disciplinary STEM subject research course into a "school-based curriculum" that was implemented at the elementary school's flexible time, guiding students' inquiry learning to promote STEM literacy. The results of this study were extended to the training of the elementary pre-service teachers in teacher training university. My follow-up research want to combine the pre-service teachers with different expertise into heterogeneous groups, and teach them cross-disciplinary curriculum design, so that they can trial teach at the elementary school to cultivate STEM literacy of elementary students.

\section{CONFLICT OF INTEREST}

"The authors declare no conflict of interest"

\section{AUTHOR CONTRIBUTION}

Author Lu executed the entire project and wrote the paper; author Hong guided our research orientation; author Chen and $\mathrm{Ma}$ were responsible for teaching and assisted in analyzing data; all authors had approved the final version.

\section{ACKNOWLEDGMENT}

This paper was written while the authors were supported by a grant from the Ministry of Science and Technology (MOST 105-2511-S-152 -010 -MY3 \& $\quad$ MOST 108-2511-H-152-003-).

\section{REFERENCES}

[1] Ministry of Education, The Outline of the 12-Year National Basic Education Curriculum Outline-Science and Technology Course Manual, Taipei, Taiwan, 2019, pp. 2-15.

[2] C. C. Lu, J. C. Hong, and F. F. Chen, "Designing a collaborative teaching of the STEAM course: The case of green building with sensor-controls," Education Journal, vol. 47, no. 1, pp. 113-133, 2019.

[3] S. Bush, "Updated: Arduino announces FPGA board, ATmega4809 in Uno Wi-Fi mk2, cloud-based IDE and IoT hardware," 2018.

[4] B. Jones. (2015). Which programming languages can you use with Arduino? [Online]. Available: 
https://www.makeuseof.com/tag/programming-languages-can-use-ard uino/

[5] D. R. Herschbach, "The STEM initiative: Constraints and challenges," Journal of STEM Teacher Education, vol. 48, no. 1, pp. 96-122, 2011.

[6] R. W. Bybee, The Case for STEM Education: Challenges and Opportunities, NSTA Science Store, 2013.

[7] A. Asghar, R. Ellington, E. Rice, F. Johnson, and G. M. Prime, "Supporting STEM education in secondary science contexts," Interdisciplinary Journal of Problem-based Learning, vol. 6, no. 2, pp. 85-125, 2012.

[8] J. J. Watters and C. M. Diezmann, "Models of community partnerships for fostering student interest and engagement in STEM," Journal of STEM Education: Innovations \& Research, vol. 14, no. 2, pp. 47-55, 2013.

[9] C. C. Lu and S. Y. Ma, "Design STEAM course to train STEAM literacy of primary students - taking "Animal mimicry beast" as an example," Journal of Research in Education Science, vol. 64, no. 3, pp 113-145, 2019.

[10] M. Baeten and M. Simons, "Student teachers' team teaching: How do learners in the classroom experience team-taught lessons by student teachers?" Journal of Education for Teaching, vol. 42, no. 1, pp. 93-105, 2016.

[11] N. Fang, "Increasing high school students' interest in STEM education through collaborative brainstorming with Yo-Yos," Journal of STEM Education: Innovations \& Research, vol. 14, no. 4, pp. 8-14, 2013.

[12] Portland State University, "Microcontrollers basic inputs and outputs (I/O),, 2018.

Copyright (C) 2020 by the authors. This is an open access article distributed under the Creative Commons Attribution License which permits unrestricted use, distribution, and reproduction in any medium, provided the original work is properly cited (CC BY 4.0).

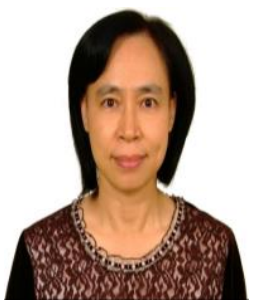

Lu Chow-Chin received the Ph.D. degree in zoology from National Taiwan University, Taipei, Taiwan, in 1994. Chow-Chin $\mathrm{Lu}$ is a professor working at the Department of Science Education, National Taipei University of Education, Taiwan. Her research interest has been focused on curriculum and instruction development, Biological concept research, elementary school teacher training, and science textbook research. She has over 100 papers published in the journals or presented in the conferences. Major journals that her papers published include Journal of Mathematics Science and Technology Education (SSCI), Learning and Individual Differences (SSCI), Thinking Skills and Creativity (SSCI), International Journal of Science and Mathematics Education (SSCI), and Asia-Pacific Forum on Science Learning and Teaching. Her research interests are focusing on three major areas: (1) Elementary school teacher training, teaching strategy mechanism and change process of teacher believes. (2)
Inquiry teaching and implementation including STEM, STEAM curriculum design. (3) Bio-bionics curriculum design and teaching.

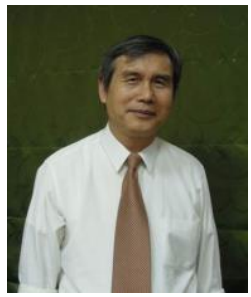

Jon-Chao Hong has received his doctoral degree in Education from the University of Illinois, Champaign-Urbana, and is currently working as a Chair professor in the department of industrial education at National Taiwan Normal University (NTNU). As the director of Digital Game-based Learning Laboratory (GBL), he has developed 9 web games, 24 educational Apps and VR for skill training and language learning. As the secretary general of Taiwan Creativity Development Association, he also organizes several creative contests relevant to STEAM, such as PowerTech Contest to invite elementary, junior and senior high school students to produce robots or miniatures in the morning and using these to compete in the afternoon to ensure students' hands-on creation without parents or teachers' assistance. As the executive secretary of International Exhibition for Young Inventors (IEYI), he also promotes the innovative contest to give students an opportunity to stimulate their science inquiry abilities, and also cultivated students' creativity and thinking attitude of STEAM.

In addition, he has published a number of academic articles in international journals related to digital game-based learning and thinking skills and creativity about 45 articles on Social Sciences Citation Index (SSCI) journals and received the Outstanding Research Prize from Ministry of Science and Technology in Taiwan.

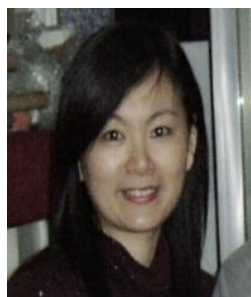

Chen Fen-Fan received the Master degree at the Department of Science Education, National Taipei University of Education, Taiwan. Fen-Fang Chen has been a teacher working at Taipei City Ren-Ai Elementary School for 29 years in Taiwan. She also served as teacher evaluation committee, committee for the examination and appraisal of teachers, and had made total 26 students got award, 13 of them got award from the national language text contests and 13 of them got award from science fair contests.

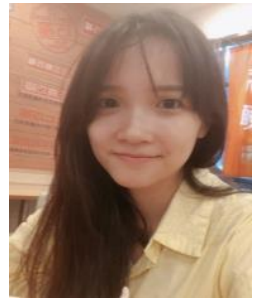

Ma Shih-Yin received the Master degree at the Department of Science Education, National Taipei University of Education, Taiwan. Shih-Yin Ma is a teacher working at New Taipei Guang Hua Elementary School and teaching science for many years. It is also one of member New Taipei Science and STEAM Counseling, and editing natural science textbooks in the team of Nanyi Book Company, Taiwan. 